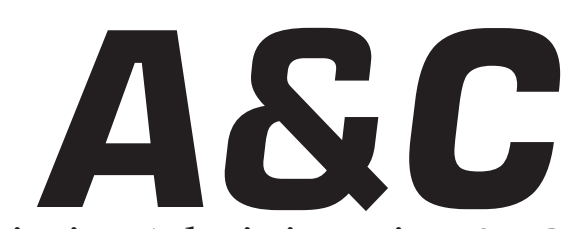

Revista de Direito Administrativo \& Constitucional

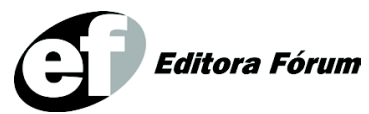

ISSN 1516-3210 


\section{A\&C REVISTA DE DIREITO ADMINISTRATIVO E CONSTITUCIONAL}

IPDA

Instituto Paranaense

de Direito Administrativo

Direção Geral

Romeu Felipe Bacellar Filho

Direção Editorial

Paulo Roberto Ferreira Motta

Direção Executiva

Emerson Gabardo

Conselho de Redação

Edgar Chiuratto Guimarães

Adriana da Costa Ricardo Schier

Célio Heitor Guimarães

\section{Conselho Editorial}

Adilson Abreu Dallari

Alice Gonzáles Borges

Carlos Ari Sundfeld

Carlos Ayres Britto

Carlos Delpiazzo

Cármen Lúcia Antunes Rocha

Celso Antônio Bandeira de Mello

Clèmerson Merlin Clève

Clóvis Beznos

Enrique Silva Cimma

Eros Roberto Grau

Fabrício Motta

Guilhermo Andrés Muñoz (in memoriam)

Jaime Rodríguez-Arana Muñoz

Jorge Luís Salomoni

José Carlos Abraão
José Eduardo Martins Cardoso
José Luís Said
José Mario Serrate Paz
Juan Pablo Cajarville Peruffo
Juarez Freitas
Julio Rodolfo Comadira
Luís Enrique Chase Plate
Lúcia Valle Figueiredo
Manoel de Oliveira Franco Sobrinho
(in memoriam)
Marçal Justen Filho
Marcelo Figueiredo
Márcio Cammarosano
Maria Cristina Cesar de Oliveira

Nelson Figueiredo

Odilon Borges Junior

Pascual Caiella

Paulo Eduardo Garrido Modesto

Paulo Henrique Blasi

Paulo Neves de Carvalho (in memoriam)

Paulo Ricardo Schier

Pedro Paulo de Almeida Dutra

Regina Maria Macedo Nery Ferrari

Rogério Gesta Leal

Rolando Pantoja Bauzá

Sérgio Ferraz

Valmir Pontes Filho

Yara Stropa

Weida Zancaner

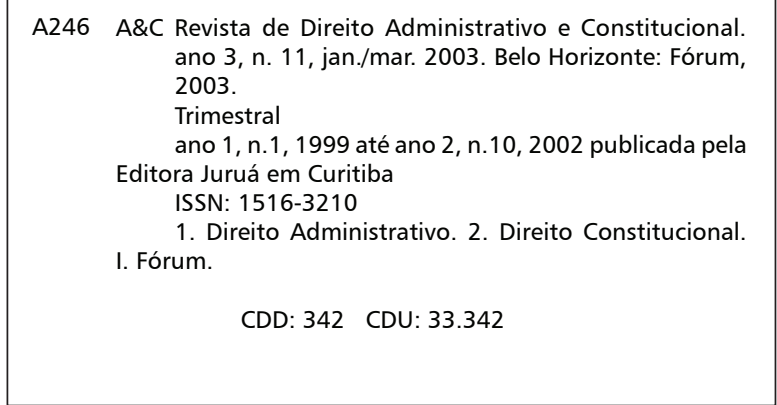

(c) Editora Fórum Ltda. 2006

Todos os direitos reservados. É proibida a reprodução total ou parcial, de qualquer forma ou por qualquer meio eletrônico ou mecânico, inclusive através de processos xerográficos, de fotocópias ou de gravação, sem permissão por escrito do possuidor dos direitos de cópias (Lei $n^{\circ}$ 9.610, de 19.02.1998).

Editora Fórum Ltda

Av. Afonso Pena, 2770 - 15\%16ª andar - Funcionários

CEP 30130-007 - Belo Horizonte/MG - Brasil

Tel.: 08007043737

Internet: www.editoraforum.com.br

e-mail: editoraforum@editoraforum.com.br
Editor responsável: Luís Cláudio Rodrigues Ferreira Projeto gráfico e diagramação: Luis Alberto Pimenta Revisora: Olga M. A. Sousa

Pesquisa jurídica: Fátima Ribeiro - OAB/MG 74868

Bibliotecária: Alessandra Rodrigues da Silva - CRB 2778/

MG 6a Região

Os conceitos e opiniões expressas nos trabalhos assinados são de responsabilidade exclusiva de seus autores.

Impressa no Brasil / Printed in Brazil

Distribuída em todo Território Nacional 


\title{
A globalização econômica e a dissipação dos direitos sociais
}

Abili Lázaro Castro de Lima

Mestre e Doutor em Direito do Estado da Universidade Federal do Paraná. Professor da disciplina Direito e Sociedade no Curso de Direito e Sociologia do Direito no PPGD da UFPR. Tutor do Grupo PET-Direito da UFPR

\begin{abstract}
"Maria Clara Machado costumava dizer aos seus alunos do Teatro Tablado, no Rio de Janeiro: 'Fechem os livros e abram os olhos'. Criada em um ambiente intelectual, autora de clássicos infantis memoráveis e havendo estudado em Paris e Londres, ela certamente não tinha desprezo pelo estudo e pelo conhecimento. Mas advertia para um dos riscos do universo acadêmico: o de bastar-se a si próprio, tornando-se insensível ao mundo real, incapaz de perceber o outro, a vida que pulsa fora dos livros, as pessoas de carne e osso, com suas necessidades e sentimentos".*
\end{abstract}

Sumário: 1 Introdução - 2 A globalização - 3 As empresas transnacionais e a nova divisão internacional do trabalho - 4 O Consenso de Washington e o neoliberalismo - 5 A crise e/ou declínio do Estado-nação - 6 A globalização econômica e suas conseqüências negativas no âmbito político - 7 A globalização econômica e suas conseqüências negativas no âmbito jurídico - 7.1 Direitos políticos - 7.2 Os direitos sociais - 8 Considerações finais

Resumo: O presente artigo realiza uma reflexão, visando demonstrar que a globalização econômica e o neoliberalismo contribuem para o esvaziamento dos direitos políticos, em face dos cidadãos terem obstada a definição dos destinos da sociedade, bem como a dissipação dos direitos sociais, em função da redução da atividade estatal, os quais proporcionam aos cidadãos condições dignas de existência, possibilitando sua atuação na seara política.

Palavras-chave: Globalização econômica. Empresas transnacionais. Estado-nação. Neoliberalismo. Direitos sociais.

\section{Introdução}

Para analisar o fenômeno da globalização, primeiramente, é importante salientar algumas dificuldades epistemológicas e metodológicas. A globalização teve várias concepções ao longo do tempo e, mesmo hoje, podemos encontrar várias significações para o mesmo fenômeno.

\footnotetext{
* BARROSO, Luis Roberto. A doutrina brasileira das efetividades. In: Temas de direito constitucional. Tomo III. Rio de Janeiro: Renovar, 2005. p. 61-62.
} 
Além disso, em que pese a profícua produção bibliográfica sobre o tema, sobretudo nos últimos seis anos, ainda não foi produzido um marco teórico que possibilitasse a leitura da globalização de forma cabal. ${ }^{1}$

Ao proceder-se o levantamento bibliográfico das obras, constata-se um grande ecletismo teórico nas abordagens sobre o tema, sem qualquer pretensão de sistematização, salvo em pouquíssimas obras, como por exemplo, nas de Boaventura de Sousa Santos. ${ }^{2}$

Uma vez que se pretende refletir sobre a realidade transnacional, encontramos ainda outro obstáculo de natureza epistemológica, decorrente do fato de que a Sociologia sempre teve o âmago das suas reflexões centrado no âmbito nacional, conforme destacado por Ulrich Beck ${ }^{3}$ e Octavio Ianni, o qual assim se manifestou a este respeito:

Os desafios epistemológicos suscitados pela formação e transformação da sociedade nacional, alimentaram a emergência e continuam a alimentar o desenvolvimento das ciências sociais, constituindo os fundamentos de seu patrimônio. A maior parte dos conceitos, categorias e leis formulados pelas ciências sociais tem por base as relações, os processos e as estruturas de dominação e apropriação, integração e antagonismo, soberania e hegemonia peculiares à realidade nacional. As principais teorias da sociedade, tais como a evolucionista, positivista, funcionalista, marxista, weberiana, estruturalista e sistêmica, entre outras, tomam por base relações, processos e estruturas próprios da sociedade nacional, como um todo ou em alguns dos seus aspectos. Apoiadas nessas teorias, a economia, política, geografia, demografia, sociologia, antropologia e história, entre outras ciências sociais, constituíram e continuam a constituir uma parte importante de seu patrimônio teórico. 'A sociologia, conforme ela aparece no seio da civilização ocidental e como a conhecemos hoje, é endemicamente preocupada com o nacional. Não reconhece uma totalidade mais ampla que a organizada politicamente na nação. O termo 'sociedade', como tem sido usado por sociólogos, independentemente da filiação teórica, é para todos os fins práticos o nome de uma entidade idêntica, em tamanho e composição, ao estado-nação. ${ }^{4}$

Outra dificuldade encontrada na análise da temática é de natureza metodológica. ${ }^{5} \mathrm{Na}$ esteira do que já ressaltamos anteriormente sobre o ponto de vista epistemológico, encontraríamos grandes dificuldades ao

\footnotetext{
Neste sentido, a resenha da obra FIORI, José Luís et al. Globalização: o fato e o mito. Rio de Janeiro: EdUERJ, 1998 sintetiza o problema: "Não há dúvida de que a palavra globalização foi cunhada no campo próprio das ideologias, transformando-se, nesta última década, num lugar-comum de enorme conotação positiva, apesar de sua visível imprecisão conceitual. É provável, inclusive, que esta palavra passe à história dos modismos sem jamais adquirir um verdadeiro estatuto teórico, mantendo-se como um conceito inacabado".

2 Destacamos a obra: SANTOS, Boaventura de Sousa. La globalización del derecho: los nuevos caminos de la regulación y la emancipación. Bogotá: Universidad Nacional de Colombia, 1998. 275 p.

3 BECK, Ulrich. Qué es la globalización. Barcelona: Paidós, 1998. p. 46, 48.

4 ANNI, Octavio. Nação e globalização. In: SANTOS, Milton et al. Fim de século e globalização. 3. ed. São Paulo: Hucitec, 1997. p. 68.

5 Adotamos o método teórico-reflexivo, uma vez que trabalharemos com categorias teóricas, bem como desenvolveremos uma análise empírico-crítica, contextualizada no cotidiano.
} 
reduzir o fenômeno da globalização a uma categoria para possibilitar sua análise. Tal obstáculo decorre do fato de que, partindo-se de vários enfoques teóricos, nem sempre a globalização é compreendida da mesma forma. Evidentemente, em face da ausência de um marco teórico, metodologicamente, optamos por analisar a globalização como um tipo ideal, o qual faz parte das teorizações de Max Weber. O conceito de tipo ideal faz parte das teorizações de Max Weber, o qual foi muito bem sintetizado por Juan Carlos Agulla. ${ }^{6}$

\section{A globalização}

Concebemos a globalização como uma crescente interconexão em vários níveis da vida cotidiana a diversos lugares longínquos no mundo. ${ }^{7}$ A globalização possui várias dimensões. Dentre elas a dimensão política, social, ambiental e cultural, sendo que centraremos o enfoque na globalização econômica, a qual entendemos que é o fio condutor das demais dimensões, bem como por nos permitir desvendar a crise dos Estados nacionais. $^{8}$

Observamos que a globalização econômica que vivenciamos é peculiar pela velocidade, extensão, interconexão da movimentação de mercadorias e informações ao redor do mundo, nunca antes visto na história, na esteira das lições de John Gray. ${ }^{9}$ Tais fatores contribuíram para o aumento da internacionalização do comércio, produzindo um crescimento gigantesco no comércio mundial, em tal proporção que tornou os Estados impotentes para controlar os fluxos de capitais, cuja dinâmica rompe ou ultrapassa as fronteiras estatais, fazendo com que as fronteiras nacionais começassem a perder sentido.

Este novo panorama é identificado como tendo se iniciado após a Segunda Guerra Mundial e se consolidando na década de oitenta. Todavia, devemos considerar que a fixação de data para a manifestação

\footnotetext{
6 Juan Carlos Agulla analisa o tipo ideal de Weber na sua obra Teoría sociológica: sistematización histórica. Buenos Aires: Depalma, 1987. p. 207-208: "Os tipos ideais são conceitos construídos racionalmente a partir da experiência, que contêm os caracteres mais gerais e típicos da ação. É dizer: são elementos obtidos da realidade empírica, porém em seu conjunto estranhos a ela. São como uma caricatura: mostram os traços mais importantes, exagerando-os. Com a ajuda destes tipos se pode chegar a estabelecer como se desenvolveria a ação se o fizera com todo o rigor como saída ao fim, sem perturbação alguma. Porém, a realidade é mais complexa, como tipo ideal só se pode indicar o grau de aproximação entre a construção ideal e o desenvolvimento real, facilitando a compreensão do sentido dos fatos, justamente por sua racionalidade".

7 Esta concepção está baseada na definição do termo dada por Anthony Giddens na obra As conseqüências da modernidade. São Paulo: UNESP, 1999. p. 69.

8 Acerca das dimensões da globalização, vide Liszt Vieira, no livro Cidadania e globalização. 2. ed. Rio de Janeiro: Record, 1997.

9 GRAY, John. Falso amanhecer: os equívocos do capitalismo global. Rio de Janeiro: Record, 1999. p. 84.
} 
do fenômeno da globalização, trata-se de uma conveniência histórica, em face da impossibilidade da sua determinação exata, consoante as lições de Hobsbawm. ${ }^{10}$

\section{As empresas transnacionais e a nova divisão internacional do trabalho}

Neste contexto, as empresas transnacionais tornam-se protagonistas privilegiados no mundo globalizado, em face do poder por elas detido, fazendo frente ao poder dos Estados. ${ }^{11}$ Surge uma nova divisão internacional do trabalho, ${ }^{12}$ a qual contribui para o reforço deste poder, fazendo com que a produção se dissemine em vários países, tornando obsoletas as fronteiras dos Estados e reduzindo o seu poder.

John Gray descreve com precisão este poder detido pela empresas transnacionais:

O crescimento e o poder das corporações multinacionais são enormes e sem precedentes. As multinacionais são hoje responsáveis por um terço da produção mundial e dois terços do comércio mundial. Mais importante é que cerca de um quarto do comércio mundial ocorre dentro de corporações multinacionais. Em

\footnotetext{
${ }^{10}$ Com relação à fixação de data para a manifestação do fenômeno da globalização, trata-se de uma conveniência histórica, em face à impossibilidade da sua determinação exata, sendo importante levar-se em consideração as lições de Eric Hobsbawm, na sua obra O novo século. São Paulo: Cia. das Letras, 2000. p. 9-10: "[...] As datas exatas sempre são questões de conveniência histórica, didática ou jornalística. [...] Em outras palavras, a escolha de uma data específica não passa de uma convenção, e não é algo pelo qual os historiadores estejam dispostos a brigar".

${ }^{11} \mathrm{O}$ gigantesco poder que as empresas nacionais detêm pode ser constatado ao cotejarmos o seu potencial econômico com o apresentado por alguns Estados, conforme se vislumbra pelos dados trazidos por DIETERICH, Heinz. La sociedad global. Buenos Aires: Editorial 21, 1999. p. 48: "As receitas combinadas dos quinhentos gigantes alcançaram em 1994 a soma de 10.245,3 trilhões de dólares, é dizer cinqüenta por cento maior que o Produto Interno Bruto (PIB) estadunidense; dez vezes maior que o PIB da América Latina e do Caribe em 1990: 25 vezes maior que o PIB do maior país latino-americano (Brasil: US\$414,06 bilhões em 1990); 43 vezes maior que o PIB mexicano (US $\$ 237,750$ bilhões) e 230 vezes maior que o venezuelano (US\$48,27 bilhões.). Os lucros combinados dos quinhentos alcançaram US $\$ 281,8$ bilhões, comparados com os PIB do Equador na ordem de US\$10,88 bilhões, El Salvador US\$5,4 bilhões; Chile US\$27,79 bilhões e Costa Rica de US\$5,7 bilhões em 1990".

${ }^{12}$ A este respeito assevera BOURDIEU, Pierre. A precariedade está hoje por toda a parte. In: BOURDIEU. Pierre. Contrafogos: táticas para enfrentar a invasão neoliberal. Rio de Janeiro: Zahar, 1998. p. 124-125: "Facilitando ou organizando a mobilidade do capital, e o 'deslocamento' para os países com salários mais baixos, onde o custo do trabalho é reduzido, favoreceu-se a extensão da concorrência entre os trabalhadores em escala mundial. A empresa nacional (ou até nacionalizada), cujo território de concorrência estava ligado, mais ou menos estritamente, ao território nacional, e que saía para conquistar mercados no estrangeiro, cedeu lugar à empresa multinacional, que põe os trabalhadores em concorrência, não mais apenas com seus compatriotas, ou mesmo, como querem nos fazer crer os demagogos, com os estrangeiros implantados no território nacional, que, evidentemente, são de fato as primeiras vítimas da precarização, mas com trabalhadores do outro lado do mundo, que são obrigados a aceitar salários de miséria. A precariedade se inscreve num modo de dominação de tipo novo, fundado na instituição de uma situação generalizada e permanente de insegurança, visando obrigar os trabalhadores à submissão, à aceitação da exploração. Apesar de seus efeitos se assemelharem muito pouco ao capitalismo selvagem das origens, esse modo de dominação é absolutamente sem precedentes, motivando alquém a propor aqui o conceito ao mesmo tempo muito pertinente e muito expressivo de flexploração. Essa palavra evoca bem essa gestão racional da insegurança,
} 
1993, de acordo com um levantamento das Nações Unidas, a produção das multinacionais girou em torno de 5,5 trilhões de dólares - o mesmo valor do que os Estados Unidos como um todo.

[...] Elas são capazes de dividir o processo de produção em discretas operações e localizá-las em diversos países ao redor do mundo. Elas são menos dependentes do que nunca das condições nacionais. Elas podem escolher os países cujos mercados de trabalho, impostos e sistemas regulamentadores e infra-estrutura sejam considerados mais adequados. A promessa de investimento interno direto e a ameaça de sua retirada têm grande influência nas opções políticas dos governos nacionais. As empresas podem agora limitar as políticas dos Estados. Existem poucos precedentes históricos deste tipo de poder privado. ${ }^{13}$

\section{Consenso de Washington e o neoliberalismo}

Para compreendermos a globalização, devemos também analisar o neoliberalismo, uma vez que suas políticas operacionalizam a globalização econômica. Trata-se de uma política econômica que surgiu no final da Segunda Guerra Mundial, no denominado Consenso de Washington, consubstanciada basicamente nas seguintes medidas: liberação dos mercados, desregulamentação, minimalismo estatal, controle da inflação, primazia das exportações, cortes nas despesas sociais, redução do déficit público, concentração do poder mercantil nas grandes empresas multinacionais e do poder financeiro nos grandes bancos transnacionais. Para a consecução de tais objetivos, foram criados alguns organismos internacionais: GATT, Banco Mundial e FMI.

Os principais teóricos do neoliberalismo são os economistas Friedrich Hayek e Milton Friedman, fundadores da Sociedade de Mont Pelèrin, que preconizam basicamente a instauração de um Estado mínimo, que se incumba de funções reduzidas, desde que se garanta uma sociedade de livre mercado em âmbito internacional, contribuindo tais teorizações para a implementação da globalização econômica.

O papel do Estado seria o de garantir e proteger o livre mercado, reduzindo-se e/ou suprimindo-se as tutelas estatais no âmbito social. Segundo os corifeus do neoliberalismo, no embate entre a democracia e a

que, instaurando, sobretudo através da manipulação orquestrada do espaço da produção, a concorrência entre os trabalhadores dos países com conquistas sociais mais importantes, com resistências sindicais mais organizadas - características ligadas a um território e a uma história nacionais - e os trabalhadores dos países menos avançados socialmente, acaba por quebrar as resistências e obtém a obediência e a submissão, por mecanismos aparentemente naturais, que são por si mesmos a sua própria justificação. Essas disposições submetidas produzidas pela precariedade são a condição de uma exploração cada vez mais 'bem-sucedida', fundada na divisão entre aqueles que, cada vez mais numerosos, não trabalham, e aqueles que, cada vez menos numerosos, trabalham, mas trabalham, cada vez mais".

${ }^{13}$ GRAY, John. Falso amanhecer: os equívocos do capitalismo global. Rio de Janeiro: Record, 1999. p. 86.

A \& C R. de Dir. Administrativo e Constitucional, Belo Horizonte, ano 6, n. 26, p. 37-58, out./dez. 2006 
liberdade, vista a última sob o enfoque econômico, esta deveria prevalecer. A aplicação das medidas econômicas de cunho neoliberal na Inglaterra nos governos Thatcher foi extremamente nefasta sob o ponto de vista das repercussões sociais. O êxito da experiência chilena é identificado como decorrente do caráter antidemocrático, autoritário e conservador imprimido pela ditadura de Pinochet.

\section{A crise e/ou declínio do Estado-nação}

Com o advento da globalização econômica, podemos constatar a crise e/ou o declínio do Estado-nação, decorrente da transnacionalização da economia implementada pelo fenômeno da globalização econômica, respaldada pela teoria econômica do neoliberalismo, em face da gradual erosão da soberania, da obsolência das fronteiras nacionais, do retraimento da esfera pública em favor do mercado e da perda dos direitos políticos dos cidadãos como resultado do esvaziamento da sua participação política.

Para constatar a crise e/ou o declínio do Estado-nação e da soberania, decorrentes da transnacionalização da economia, iremos apresentar alguns de seus elementos indicativos.

Hobsbawm sintetiza o panorama do declínio do Estado-nação asseverando que:

Quando a economia transnacional estabeleceu o seu domínio sobre o mundo, solapou uma grande instituição, até 1945 praticamente universal: o Estado-nação territorial, pois um Estado assim já não poderia controlar mais que uma parte cada vez menor dos seus assuntos. Organizações cujo campo de ação era efetivamente limitado pelas fronteiras de seu território, como sindicatos, parlamentos e sistemas públicos de rádio e televisão nacionais, saíram portanto perdendo, enquanto organizações não limitadas desse jeito, como empresas transnacionais, o mercado de moeda internacional e os meios de comunicação da era do satélite, saíram ganhando. O desaparecimento das superpotências, que podiam de qualquer modo controlar os Estados-satélites, iria reforçar essa tendência. Mesmo a mais insubstituível função que os Estados-nações haviam desenvolvido durante o século, a de redistribuir sua renda entre suas populações através das "tendências sociais" dos serviços de previdência, educação e saúde, e outras alocações de fundos, não mais podia ser territorialmente auto-suficiente em teoria, embora a maior parte tivesse de continuar sendo na prática, a não ser onde entidades supranacionais como a Comunidade ou União Européia a complementasse em alguns aspectos. Durante o auge dos teólogos do livre mercado, o Estado foi solapado mais ainda pela tendência de desmontar as atividades então exercidas, em princípio, por órgãos públicos deixando-as entregues ao "mercado". ${ }^{14}$

Os sintomas da crise ou do declínio do Estado-nação em face das

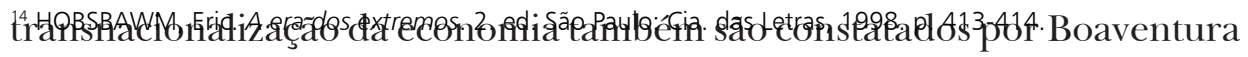


de Sousa Santos, sobretudo enunciando as mazelas da globalização dela decorrentes no plano político-jurídico:

[...] Ao contrário do que aconteceu em tempos passados, a força diretriz por trás da transformação do Estado e da sua legalidade é a intensificação das práticas transnacionais e as interações globais; sob essas pressões, as funções reguladoras do Estado-nação passariam a ser derivadas, é dizer, passam a depender dos imperativos da globalização econômica tal como são formulados pelas organizações internacionais (o Banco Mundial, a Organização Mundial do Comércio, o Fundo Monetário Internacional, etc.) ou pelas próprias empresas multinacionais dos estados hegemônicos, na defesa dos interesses destas, sobretudo as norte-americanas. Um exemplo desta situação encontra-se na pressão dos Estados Unidos em favor da adoção de novas leis sobre patentes a nível global. Nesta circunstância, a regulação estatal, sobretudo na periferia e na semi-periferia do sistema mundial, se converte numa espécie de subcontratação ou franquia política.

[...] A ideologia e a prática do liberalismo econômico impulsionada por forças políticas domésticas e internacionais, combinadas com as práticas das empresas transnacionais, têm levado certamente a uma perda relativa do papel de protagonista do Estado-nação dentro do sistema mundial. A maioria dos autores tendem a aceitar que, em áreas decisivas, o Estado está sendo desconectado tanto do capital como do trabalho nacionais, perdendo a sua capacidade de garantir por si mesmo os ajustes institucionais necessários para a uma reprodução e uma acumulação estáveis. [...]. ${ }^{15}$

Neste sentido, consoante Boaventura, a concepção de soberania perde todo o sentido no mundo globalizado:

[...] a operação dos Estados num sistema internacional cada vez mais complexo limita sua autonomia (em certas esferas de forma radical) e menospreza progressivamente sua soberania. Todas as concepções que interpretam a soberania como uma forma de poder público ilimitado e indivisível - materializado canonicamente nos Estados-nação individuais - resultam obsoletas. A soberania tem que ser concebida hoje em dia como uma faculdade dividida entre múltiplas agências - nacionais, regionais e internacionais - e limitada pela natureza mesma desta pluralidade. ${ }^{16}$

Esta perda da soberania e da eficácia dos Estados-nação não corresponde, na visão de Boaventura de Sousa Santos, um aumento de poder nas esferas transnacionais para a solução dos problemas globais:

A perda da centralidade institucional e de eficácia reguladora dos Estados nacionais, por todos reconhecida, é hoje um dos obstáculos mais resistentes à

\footnotetext{
15 SANTOS, Boaventura de Sousa. La globalización del derecho. p. 37, 87.

${ }^{16}$ HELD, David. La democracia y el orden global: Del Estado moderno al gobierno cosmopolita. Barcelona: Paidós, 1997. p. 169
} 
busca de soluções globais. É que a erosão do poder dos Estados nacionais não foi compensada pelo aumento de poder de qualquer instância transnacional com capacidade, vocação e cultura institucional voltadas para a resolução solidária dos problemas globais. De fato, o caráter dilemático da atuação reside precisamente no fato da perda de eficácia dos Estados nacionais se manifestar antes na incapacidade destes para construírem instituições internacionais que colmatem e compensem essa perda de eficácia. ${ }^{17}$

Os motivos da deterioração do Estado-nação, consoante Hobsbawm, seriam os seguintes:

[...] algumas características do panorama político global se destacavam. A primeira, como já se observou, era o enfraquecimento do Estado-nação, instituição central da política desde a Era das Revoluções devido a tanto seu monopólio do poder público e da lei quanto porque constituía o campo efetivo da ação política para a maioria dos finns. O Estado-nação estava sendo erodido de duas formas, de cima e de baixo. Perdia rapidamente poder e função para várias entidades supranacionais, e, na verdade, de forma absoluta, na medida em que a desintegração de grandes Estados e impérios produzia uma multiplicidade de Estados menores, demasiado fracos para defender-se numa era de anarquia internacional. Perdia também, como vimos, seu monopólio de poder efetivo e seus privilégios históricos dentro de suas fronteiras, como testemunham a ascensão da segurança privada e dos serviços postais privados competindo com o correio, até então praticamente controlado em toda a parte por um ministério de Estado. ${ }^{18}$

Concordamos com Octavio Ianni que reconhece a limitação da soberania do Estado-nação e o abalo na sua base, ${ }^{19}$ não aceitando a idéia do seu fim, pois tais categorias seriam criadas e recriadas pelo capitalismo, consoante suas necessidades.

A partir do poder das empresas transnacionais, estamos presenciando uma ruptura histórica que marca o declínio do Estado-nação e o surgimento de "novos e poderosos centros mundiais de poder, soberania e hegemonia". Entendemos, na esteira do pensamento de Ianni, mesmo assim, o Estado-nação continuaria existindo, porém com um novo significado: as funções do Estado permanecem no âmbito da globalização, todavia, o seu papel tende a reduzir-se gradativamente, havendo uma redefinição do mesmo, porém com um novo significado, ou seja, nada mais

\footnotetext{
17 SANTOS, Boaventura de Sousa. Pela mão de Alice: o social e o político na pós-modernidade. 2. ed. São Paulo: Cortez, 1996. p. 300.

18 HOBSBAWM, Eric. A era dos extremos. 2. ed São Paulo: Cia das Letras, 1998, p. 553-554.

${ }^{19}$ A este respeito, IANNI, Octavio. Teorias da globalização. 2. ed. Rio de Janeiro: Civilização Brasileira, 1996. p. 34 afirma: "Quando se leva às últimas conseqüências 'o princípio da maximização da acumulação do capital', isto se traduz em desenvolvimento intensivo e extensivo das forças produtivas e das relações de
} 
seria do que um emblema, uma ficção:

Ocorre que a economia-mundo, ou sistema-mundo, em toda a sua complexidade não só econômica, mas também social, política e cultural, sempre transcende tudo o que é local, nacional e regional. Repercute por todos os cantos, perto e longe. Os colonialismos e imperialismos espanhol, português, holandês, belga, francês, alemão, russo, japonês, inglês e norte-americano sempre constituíram e destruíram fronteiras, soberanias e hegemonias, compreendendo tribos, clãs, nações e nacionalidades. São muitos os que reconhecem nos Estados nacionais asiáticos, africanos e latino-americanos foram desenhados, em sua quase totalidade, pelos colonialismos e imperialismos europeus, segundo modelos geo-histórico e teórico, ou ideológico, configurado no Estado-nação que se formou e predominou na Europa.

O emblema o Estado-nação sempre teve as características simultâneas e contraditórias de realidade geo-histórica e ficção. Na época da globalização, e provavelmente de forma muito mais marcante, torna-se mais ficção. Tal emblema está atravessado por relações, processos e estruturas altamente determinados pela dinâmica dos mercados, da desterritorialização das coisas, gentes e idéias, enquanto a reprodução ampliada do capital se globaliza, devido ao desenvolvimento extensivo e intensivo do capitalismo, compreendendo as forças produtivas, tais como o capital, a tecnologia, a força de trabalho e a divisão do trabalho social, sempre envolvendo as instituições, os padrões socioculturais e os ideais relativos à racionalização, produtividade, lucratividade, quantidade..$^{20}$

No próximo item, iremos refletir sobre as conseqüências negativas do novo panorama nos contextos político e jurídico engendrados pela globalização econômica e pelo neoliberalismo.

\section{A globalização econômica e suas conseqüências negativas no âmbito político}

As análises da globalização econômica e do neoliberalismo foram relevantes, pois propiciam a abordagem das conseqüências negativas causadas no plano político-jurídico, ${ }^{21}$ decorrentes do processo de trans-

produção, em escala mundial. Desenvolvem-se relações, processos e estruturas de dominação política e apropriação econômica em âmbito global, atravessam os territórios e fronteiras, nações e nacionalidades. Tanto é assim que as organizações multilaterais passam a exercer as funções de estruturas mundiais de poder, ao lado das estruturas mundiais de poder constituídas pelas corporações transnacionais. É claro que não se apagam o princípio da soberania nem o estado-nação, mas são radicalmente abalados em suas prerrogativas, tanto que se limitam drasticamente, ou simplesmente anulam, as possibilidades de projetos de capitalismo nacional e socialismo nacional. Acontece que o capitalismo, enquanto modo de produção e processo civilizatório, cria e recria o Estado-nação, assim como o princípio da soberania que define a sua essência. Ainda que esta entidade, isto é, o Estado-nação soberano, permaneça, ou mesmo recrie, está mudando de figura, no âmbito das configurações e movimentos da sociedade global. Aliás, não é por acaso que se multiplicam os estudos e os debates acerca do Estado-nação, enquanto processo histórico e invenção, uma realidade persistente e problemática; e que se encontra em crise no final do século XX, quando da globalização do capitalismo".

${ }^{20}$ IANNI, Octavio. Teorias da globalização. 2. ed. Rio de Janeiro: Civilização Brasileira, 1996. p. 40-41. 
nacionalização do espaço político decorrente da globalização, quando a noção de política perde o seu referencial de manifestação num espaço político definido territorialmente, transcendendo as fronteiras do Estado-nação.

No tocante às mazelas políticas, podemos vislumbrar que o espaço público está se esvanecendo na medida em que as decisões transcendem o âmbito do Estado, máxime quando definidas pelas empresas transnacionais e organismos internacionais, implicando o enfraquecimento do poder local (Estado-nação) e produzindo apatia política, uma vez que a participação política dos cidadãos cada vez mais perde significância, eis que o indivíduo sente-se distante dos centros decisórios, que se encontram fora do lugar onde vive.

No contexto do mundo globalizado, os cidadãos acabariam assumindo a condição de consumidores ${ }^{22}$ ensejando comportamentos egoístas, despertando o individualismo, rompendo os elos de solidariedade social e de compartilhamento de um destino comum na sociedade, peculiaridade que poderá resultar no perecimento da política. ${ }^{23}$ Constatamos ainda, o esvaziamento do debate político, eis que as diretrizes neoliberais

\footnotetext{
${ }^{21}$ Para uma análise mais profunda das conseqüências negativas da globalização nas searas política e jurídica, vide o capítulo III da obra do autor, Globalização econômica, política e direito: análise das mazelas no plano político-jurídico, Sérgio Fabris: Porto Alegre, 2002.

22 Alain Touraine, na obra O que é a democracia? Petrópolis: Vozes, 1995, p. 178-179, demonstra esta infeliz condição e suas conseqüências nefastas para a democracia: "A democracia foi conquistadora quando colocou suas esperanças na razão e no trabalho para combater os privilégios e tradições. Atualmente, está mais inquieta porque a globalização esmaga a diversidade das culturas e experiências pessoais e porque o cidadão se transforma em consumidor. Inquieta, sobretudo, porque está saindo de um longo período de dominação dos regimes totalitários ou autoritários que impuseram seu poder absoluto em nome de uma revolução popular e porque, hoje em dia, no próprio interior das sociedades que são protegidas do arbitrário, exercem-se forças que destroem a democracia. A opinião pública pode se transformar em consumo de programas e a defesa do indivíduo pode se degradar em particularismos, seitas ou até mesmo, obsessão de identidade pessoal ou coletiva. A separação crescente entre mundo dos objetos e mundo da cultura faz desaparecer o sujeito que se define pela produção de sentido a partir da atividade, pela transformação de uma situação em ação e em produção de si. A democracia não é a submissão do indivíduo ao bem comum; pelo contrário, coloca as instituições a serviço da liberdade e da responsabilidade pessoais. No entanto temos dificuldade de perceber o espaço do sujeito entre as massas que o enquadram e ameaçam esmagálo: por um lado, as filiações sociais e culturais, por outro, o mercado ou os sistemas técnicos. A crise da modernidade vem do fato de deixarmos de nos sentir donos do mundo que construímos: este impõe-nos sua lógica, a do lucro ou a do poder, de modo que, para lhe oferecer resistência, devemos fazer apelo ao que há de menos moderno em nós e mais ligado a uma história e comunidade"

${ }^{23}$ Neste sentido, Milton Santos, no livro Por uma outra globalização: do pensamento único à consciência universal. Rio de Janeiro: Record, 2000. p. 60-61: "Na verdade, a perversidade deixa de se manifestar por fatos isolados, atribuídos a distorções de personalidade, para se estabelecer como um sistema. Ao nosso ver, a causa essencial da perversidade sistêmica é a instituição, por lei geral da vida social, da competitividade como regra absoluta, uma competitividade que escorre sobre todo o edifício social. O outro, seja ele uma empresa, instituição ou indivíduo, aparece como um obstáculo à realização dos fins de cada um e deve ser removido, por isso sendo considerado uma coisa. Decorrem daí a celebração dos egoísmos, o alastramento dos narcisismos, a banalização da guerra de todos contra todos, com a utilização de qualquer que seja o meio para obter o fim colimado, isto é, competir e, se possível, vencer. Daí a difusão, também generalizada,
} 
dominam o processo decisório. Instaura-se o denominado pensamento único, impondo-se como um dogma, segundo o princípio que o econômico prevalece sobre o político.

Podemos identificar ainda a existência de uma crescente exclusão social, caracterizada pela precarização das condições de trabalho, pela disseminação do desemprego crônico, baixos níveis salariais, perda das garantias sociais dos cidadãos e pela geração de um quadro de pobreza estrutural, ${ }^{24}$ que compromete a participação dos cidadãos nos âmbitos político e jurídico, eis que os cidadãos não têm garantidas condições mínimas e dignas de existência para participarem politicamente.

\section{A globalização econômica e suas conseqüências negativas no}

de outro subproduto da competitividade, isto é, a corrupção. Esse sistema da perversidade inclui a morte da Política (com um $\mathrm{P}$ maiúsculo), já que a condução do processo político passa a ser atributo das grandes empresas. Junte-se a isso o processo de conformação da opinião pelas mídias, um dado importante no movimento de alienação trazido com a substituição do debate civilizatório pelo discurso único do mercado. Daí o ensinamento e o aprendizado de comportamentos dos quais estão ausentes objetivos finalísticos e éticos. Assim elaborado, o sistema de perversidade legitima a preeminência de uma ação hegemônica mas sem responsabilidade, a instalação sem contrapartida de uma ordem entrópica, com a produção 'natural' da desordem.

Para tudo isso, também contribui o estabelecimento do império do consumo, dentro do qual se instalam consumidores mais que perfeitos (SANTOS, M. O espaço do cidadão. 1988), levados à negligência em relação à cidadania e seu corolário, isto é, o menosprezo quanto à liberdade, cujo culto é substituído pela preocupação com a incolumidade. Esta reacende egoísmos e é um dos fermentos da quebra da solidariedade entre as pessoas, classes e regiões. Incluam-se, também, nessa lista dos processos característicos a instalação do sistema da perversidade, a ampliação das desigualdades de todo gênero: interpessoais, de classes, regionais, internacionais. Às antigas desigualdades, somam-se novas".

24 Este quadro é descrito por Milton Santos, no livro Por uma outra globalização, p. 67-69, nos seguintes termos: "A política, por definição, é sempre ampla e supõe uma visão de conjunto. Ela apenas se realiza quando existe a consideração de todos e de tudo. Quem não tem visão de conjunto não chega a ser político. E não há política apenas para os pobres, como não há apenas para os ricos. A eliminação da pobreza é um problema estrutural. Fora daí o que se pretende é encontrar formas de proteção a certos pobres e a certos ricos, escolhidos segundo os interesses dos doadores. Mas a política tem de cuidar do conjunto de realidades e do conjunto de relações. Nas condições atuais, e de um modo geral, estamos assistindo à não-política, isto é, à política feita pelas empresas, sobretudo as maiores. Quando uma grande empresa se instala, chega com suas normas, quase todas extremamente rígidas. Como essa normas rígidas são associadas ao uso considerado adequado das técnicas correspondentes, o mundo das normas se adensa porque as técnicas em si mesmas também são normas. Pelo fato de que as técnicas atuais são solidárias, quando uma se impõe cria-se a necessidade de trazer outras, sem as quais aquela não funciona bem. Cada técnica propõe uma maneira particular de comportamento, envolve suas próprias regulamentações e, por conseguinte, traz para os lugares novas formas de relacionamento. 0 mesmo se dá com as empresas. É assim que também se alteram as relações sociais dentro de cada comunidade. Muda a estrutura do emprego, assim como as outras relações econômicas, sociais, culturais e morais dentro de cada lugar, afetando igualmente o orçamento público, tanto na rubrica da receita como no capítulo da despesa. Um pequeno número de grandes empresas que se instala acarreta para a sociedade como um todo um pesado processo de desequilíbrio.Todavia, mediante o discurso oficial, tais empresas são apresentadas como salvadoras dos lugares e são apontadas como credoras de reconhecimento pelos seus aportes de emprego e modernidade. Daí a crença de sua indispensabilidade, fator da presente guerra entre lugares e, em muitos casos, de sua atitude de chantagem frente ao poder público, ameaçando ir embora quando não atendidas em seus reclamos. Assim, o poder público passa a ser subordinado, compelido, arrastado. À medida que se impõe esse nexo de grandes empresas, instala-se a semente da ingovernabilidade, já fortemente implantada no Brasil, ainda que sua dimensão não tenha sido adequadamente avaliada À medida que os institutos encarregados de cuidar do interesse geral são enfraquecidos, com o abandono da noção e da prática da solidariedade, estamos, pelo menos a médio prazo, produzindo as precondições da fragmentação e da desordem, claramente visíveis no país, por meio do comportamento dos territórios, isto é, da crise praticamente geral dos estados e dos municípios".

${ }^{25}$ Neste particular, vide José Eduardo Faria, na obra FARIA, José Eduardo. O Direito na economia globalizada.

A \& C R. de Dir. Administrativo e Constitucional, Belo Horizonte, ano 6, n. 26, p. 37-58, out./dez. 2006 


\section{âmbito jurídico}

\subsection{Direitos políticos}

No que pertine às conseqüências negativas no âmbito jurídico, tendo em vista a diminuição do papel do Estado e, conseqüentemente, da esfera pública, a qual cada vez mais perde importância em face do poder detido pelas empresas transnacionais e pelas organizações internacionais, a globalização econômica contribui para o esvanecimento dos direitos políticos, eis que ela compromete a definição dos destinos da sociedade pelos cidadãos.

A fragmentação social engendra o esvaziamento do indivíduo, em face do poder político estar cada vez mais à mercê das regras do mercado definidas pelas empresas transnacionais, tornando a economia o parâmetro das decisões políticas e jurídicas. Estamos assistindo a transição de uma sociedade de homens para uma sociedade de organizações. ${ }^{25}$

\subsection{Os direitos sociais}

Os direitos sociais são representativos da garantia do cidadão de ter condições mínimas de bem-estar, as quais garantem a sua participação na sociedade, consoante padrões dignos de existência nela, na busca do equilíbrio social.

Trata-se de "direitos de inserção", que tem por escopo uma "justiça compensatória, distributiva e niveladora", ${ }^{26}$ conforme os concebe José Eduardo Faria e que estão sobretudo ligados às instituições educacionais e aos serviços sociais, bem como uma de suas manifestações mais profícuas encontra-se atrelada aos direitos sociais relativos ao trabalho, também designados como Direito do Trabalho.

Não é estéril lembrar que os direitos sociais não se implementam por si sós, conforme muito bem salientou José Eduardo Faria, ou seja, não são auto-executáveis e não resultam do exercício dos cidadãos. Eles dependem do Estado para serem efetivados e, uma vez que a globalização econômica e o neoliberalismo obstam cada vez mais a sua concretização, fazem com que eles pereçam, recrudescendo, conseqüentemente, o quadro

São Paulo: Malheiros, 1999

${ }^{26}$ FARIA, José Eduardo. O direito na economia globalizada. São Paulo: Malheiros, 1999. p. 273, 276.

27 Esta perspectiva foi muito bem elucidada por José Eduardo Faria, no livro FARIA, José Eduardo. O direito na

A \& C R. de Dir. Administrativo e Constitucional, Belo Horizonte, ano 6, n. 26, p. 37-58, out./dez. 2006 


\section{de exclusão social. ${ }^{27}$}

Assim, fica evidenciado que a globalização e o neoliberalismo constituem um óbice à efetividade dos direitos sociais. Neste diapasão, como corolário da miniaturização do Estado, concebida como a erosão da soberania do Estado e de suas capacidades regulatórias, que está ocorrendo um processo de desuniversalização dos direitos sociais, eis que a redução da atividade estatal acaba por dissipá-los, posto que a atuação do Estado é indispensável para sua implementação, conforme as teorizações de José Affonso Dallegrave Neto:

Com o chamado Estado-Providência (welfare state), no início deste século, sobreveio o fenômeno da universalização dos direitos sociais. Foi então que as chamadas constituições programáticas passaram a garantir em seu bojo inúmeros direitos sociais e trabalhistas.

O que outrora ficava a cargo de leis esparsas, a partir de então foi guindado a um status constitucional, a Constituição do México (1917), a Constituição Soviética (1918) e a Constituição de Weimar (1919) que, "adotando o intervencionismo estatal nas relações de trabalho, reconheceu conquistas econômicas e sociais, tais como o direito ao trabalho, a salário condigno, associação sindical, greve, limite de duração de jornada, descanso semanal, férias, previdência social".

Estas cartas influenciaram as demais nações ocidentais a também assegurar direitos sociais em suas constituições, passando a ser sinônimo de país avançado aquele que melhor contemplava seu povo com direitos humanos, políticos e sociais.

A atual proposta do neoliberalismo propugna pela desuniversalização destes direitos sociais $[\ldots]^{28}$

economia globalizada. São Paulo: Malheiros, 1999. p. 272-273: "Ao contrário dos direitos individuais, civis e políticos e das garantias fundamentais desenvolvidos pelo liberalismo burguês com base no positivismo normativista, cuja eficácia requer apenas que o Estado jamais permita sua violação, os 'direitos sociais' não podem simplesmente ser atribuídos aos cidadãos. Como não são self-executing nem muito menos fruíveis ou exeqüíveis individualmente, esses direitos têm sua efetividade dependente de um welfare commitment. Em outras palavras, necessitam de uma ampla e complexa gama de programas governamentais e de políticas públicas dirigidas a segmentos específicos da sociedade; políticas e programas especialmente formulados, implementados e executados com o objetivo de concretizar esses direitos e atender às expectativas por eles geradas com sua positivação. A inexistência dessas políticas e desses programas, é evidente, acaba implicando automaticamente a denegação desses direitos. Os textos legais baseados nessa perspectiva 'social' não se limitam, dessa maneira, a institucionalizar a liberdade 'negativa', como se ela fosse toda a liberdade (e não apenas uma das suas dimensões); em outras palavras, não se circunscrevem a estabelecer e/ou delegar competências, a fixar obrigações e/ou enunciar princípios - função tradicional dos institutos jurídicos do Estado liberal clássico. Oriundos das mais variadas fontes materiais, muitas delas conflitantes entre si, e editados em tempos distintos, tutelando interesses que nem sempre são combináveis e conciliáveis, esses textos se destacam por exigir tratamentos diferenciados em favor de determinados segmentos sociais. Contrapondo-se à idéia de igualdade na acepção formal (e liberal-burguesa) do termo, que é um dos pressupostos básicos do paradigma da dogmática jurídica, o direito social é, assim, um 'direito das desigualdades' ou de 'discriminações positivas', mais precisamente, à luz dos problemas discutidos ao longo deste capítulo, é um 'direito de inserção'. 
As teorizações de Manoel Eduardo Alves Camargo e Gomes elucidam os mecanismos e a ideologia das políticas neoliberais que expulsam para fora da esfera pública as tutelas relativas aos direitos sociais:

Assim, não só a hiperinflação, mas todas as insuficiências dos Estados de Bem-Estar (déficit público, dívida interna e externa, ineficiência burocrática, corrupção, marginalização, desemprego, sucateamento dos bens e serviços públicos, incapacidade do Estado em expandir seus ingressos pela via tributária, para ficar em alguns exemplos) foram utilizadas e ampliadas pelo projeto neoliberal para, no dizer de Borón, "satanizar" a figura do Estado.

A ideologia, na forma de propaganda simplificadora, do Estado incompetente, ineficiente, corrupto, obeso e de um mercado austero, ágil, eficiente, probo, voltado para a qualidade total, é utilizada em dois sentidos: de um lado, legitima importantes itens da pauta neoliberal; de outro, ampliando enormemente o déficit de legitimação política do Estado, reduz seu custo, legitimando o modelo preconizado pelos neoliberais. O Estado que tudo prometia e pouco cumpria é deslegitimado para legitimar um Estado que tão pouco promete e, por isso, aparenta tudo cumprir.

Não subestimemos: sem rupturas econômicas, sociais ou políticas, em ambiente democrático (salvo alguns casos como o do Chile e do Peru), desonerou-se o Estado de um enorme conjunto de funções sociais, desuniversalizando-se os serviços sociais e liberando-os para o mercado.

A suposta excelência do setor privado faz com que não cobremos do Estado energia elétrica, distribuição de petróleo e seus derivados, extração de minerais estratégicos, tratamento de água, educação, saúde, transporte, comunicação, calçamento público... A legitimação, assim, assume outra feição: a do Estado mínimo, ágil, eficaz, cuja função básica deve estar adstrita à garantia da sanidade do mercado, em especial, pela ordem e segurança das relações privadas.

Assim, o processo de produção de tutelas jurídico-políticas toma, no contexto da legitimação política, outro sentido, que restringe enormemente o potencial de inclusão de demandas sociais majoritárias no âmbito do ordenamento jurídico. A pressão de inclusão destas demandas perde sua força, vez que o Estado, "explicitamente", deixa de ter como função a prestação de certas tutelas que antes lhe eram acometidas. Sua sustentação política é posta em outro lugar. A legitimação, adstrita a pressupostos tais como eficácia, agilidade e baixo custo, vai perdendo sua natureza política e social, em troca de critérios de avaliação estritamente econômicos. E estes passam, de forma crescente, a nortear o processo de recepção das demandas sociais na forma de tutelas jurídico-políticas. ${ }^{29}$

Também podemos constatar nitidamente o processo de redução/ supressão gradual dos direitos sociais, quando analisamos os direitos sociais relativos ao trabalho, ${ }^{30}$ ou como são normalmente conhecidos, os direitos

\footnotetext{
${ }^{28}$ DALLEGRAVE NETO, José Affonso. O Estado neoliberal e seu impacto sócio-jurídico. In: MACCALÓZ, Salete Maria et al. Globalização, neoliberalismo e direitos sociais. Rio de Janeiro: Destaque, 1997. p. 88-89.

${ }^{29}$ GOMES, Manoel Eduardo Alves Camargo e. Apontamentos sobre alguns impactos do projeto neoliberal no processo de formação de tutelas jurídico-políticas. In: MARQUES NETO, Agostinho Ramalho et al. Direito e neoliberalismo: elementos para uma leitura interdisciplinar. Curitiba: EDIBEJ, 1996. p. 127-129.
} 
trabalhistas. Não é estéril enfatizar a relevância de tais direitos sociais no contexto da cidadania, em face da sua contribuição no sentido de conter a exploração sem escrúpulos do trabalho humano, tutelando os direitos dos trabalhadores no sentido de oportunizar-lhes condições dignas de existência e de participação, os quais resultaram de lutas travadas no seio da esfera pública.

Em decorrência desta desregulamentação no âmbito social, ou seja, com a redução ou a supressão das regras e das normas emanadas no Estado no sentido de tutelar as garantias sociais dos trabalhadores, a globalização econômica põe em xeque as condições sociais para a manutenção da cidadania de forma digna, recrudescendo, desta forma, o quadro de exclusão social, ante à impossibilidade do Estado, debilitado em face à redução da esfera pública, de tutelar as garantias sociais dos trabalhadores.

A supressão das tutelas jurídicas no que concerne às garantias sociais dos trabalhadores manifesta-se basicamente através de dois mecanismos: a flexibilização ${ }^{31}$ e a desregulamentação dos direitos trabalhistas.

Para elucidar esta dicotomia, iremos nos valer das lições de Benedito Calheiros Bonfim:

A desregulamentação do Direito do Trabalho, por alguns defendida, não se confunde com a flexibilização das relações de trabalho, hoje praticada na Europa Ocidental e em países que seguem o seu modelo. Esta última corresponde a uma fenda no princípio da inderrogabilidade das normas de ordem pública

\footnotetext{
30 Júlio Cesar do Prado Leite, no artigo A internacionalização da economia e a proteção do trabalhador. In: MACCALÓZ, Salete Maria et al. Globalização, neoliberalismo e direitos sociais. Rio de Janeiro: Destaque, 1997. p. 29, sintetiza com mestria a dimensão dos direitos sociais relativos ao trabalho: "Duas realidades, todos sabemos, marcam o Direito Social: o Direito ao Trabalho e o Direito do Trabalho. O último - Direito do Trabalho - consiste, como bem define Riva Sanseverino, essa notável jurista italiana, em representar a solução normativa que um determinado país deu, em determinado momento histórico, a todo o complexo de problemas políticos e econômicos que cercam a relação de emprego, de tal modo que compense, usando de acuidade e temperança, a superioridade econômica do empregador com a devida superioridade jurídica conferida pelo Estado ao trabalhador, de modo que se preserve no contrato o que se convencionou nomear de 'dignidade humana'. Já o Direito ao Trabalho é tão fundamental à Paz Social quanto o Direito regulador dos contratos de trabalho. É preciso que o Estado, que é a nação politicamente organizada, enseje meios e abra iniciativas próprias ou estimule iniciativas particulares, de modo a que o número de postos de trabalho se amplie, a fim de absorver todos os que já tenham condições de adentrar ao mercado laboral".

${ }^{31}$ Adotamos a acepção "flexibilização" dos direitos trabalhistas, por ser a mais empregada e, por este fundamento, ser representativa de um acordo semântico disseminado no meio jurídico que expressa a redução dos direitos trabalhistas. Todavia, para alguns o correto seria a denominação "flexibilidade", conforme se infere nas asserções de Reinaldo Pereira e Silva, no artigo O neoliberalismo e o discurso da flexibilidade dos direitos sociais relativos ao trabalho. In: ARRUDA JÚNIOR, Edmundo Lima de: RAMOS, Alexandre (Org.). Globalização, neoliberalismo e o mundo do trabalho. Curitiba: IBEJ, 1998. p. 64: "O termo flexibilidade (do latim flexibilitate), na acepção mais encontradiça nos escritos jurídicos, diz respeito a uma qualidade constante de certo direito, atributo de adaptabilidade ao meio em que tende a incidir,
} 
e no da inalterabilidade in pejus das condições contratuais ajustadas em favor do trabalhador, visando a facilitar a implementação de nova tecnologia ou preservar a saúde da empresa e a manutenção de empregos. O direito comparado revela que ela procura ajustar a aplicação da norma legal a peculiaridades regionais, empresariais ou profissionais, ainda que alterando condições contratuais para a consecução dessas metas. [...]

Na flexibilização sobrevive a legislação de proteção ao trabalho com algumas normas gerais irrenunciáveis e outras que admitem as adaptações precitadas; na desregulamentação o Estado não intervém nas relações de trabalho, para que a autonomia privada, coletiva ou individual, disponha sem limitações legais, sobre as condições de trabalho. Seria o retorno à fase histórica em que as péssimas condições de trabalho justificaram a ampla e diversificada reação que fundamentou o advento da legislação social-trabalhista. ${ }^{32}$

No tocante à desregulamentação dos direitos trabalhistas, Salete Maria Polita Maccalóz desvenda a forma ardilosa e sub-reptícia segundo a qual a desregulamentação se manifesta, aduzindo que "esta é uma 'eficiente' desregulamentação. Não enfrenta o ônus político da revogação incondicional das leis existentes. A legislação é mantida apenas para sustentação do discurso político falacioso, da existência de duplo regime; o antigo ‘intocável', mas que não protege mais ninguém, pela ausência de destinatários, e, o novo cuja finalidade menos protecionista tem por objetivo ampliar o mercado de trabalho". ${ }^{3}$

Jorge Eduardo Levi Mattoso apresenta de que forma a flexibilização se manifesta dentro das relações de trabalho:

Flexibilidade torna-se, assim, o termo do momento, da modernidade. Além das empresas, agora favorecidas por tecnologias que efetivamente favorecem a sua maior flexibilidade, também os salários, os trabalhadores, o mercado de trabalho, o direito, etc., deveriam tornar-se mais flexíveis. Tudo que é flexível torna-se moderno; as regras, as normas, a segurança são o atraso. Poder-se-ia mesmo substituir o termo insegurança por flexibilidade e aparentemente pouco

e o termo flexibilização, ausente dos dicionários, apesar de mais empregado do que o antecedente, a um processo de adaptação do direito, algo relativo a uma qualidade ainda a ser alcançada por ele. É nesse sentido que Júlio Assumpção Malhadas elucida: 'flexibilidade é elasticidade, facilidade de manuseio, adaptabilidade, e flexibilização é dar flexibilidade a...'. Nesse passo, a 'flexibilidade' de direitos há de ser a adaptabilidade das normas, a sua facilidade do manuseio, e flexibilização de direitos, tornar adaptáveis e de fácil manuseio as normas, ou fazer normas apropriadas e facilmente manejáveis. Com base nessas considerações, não é difícil distinguir flexibilidade de flexibilização. Mediante o emprego do primeiro termo, trabalha-se com o tempo presente, com o que já existe; através do segundo, trabalha-se com o tempo futuro, com o que existe somente enquanto 'meta a ser conquistada'. Não obstante isso, o uso pelos autores de ambos os termos se processa sem qualquer critério, [...]". Sobre o tema, vide também Cássio Mesquita Barros, no artigo Flexibilização do direito do trabalho. Revista LTr, São Paulo, v. 59, p. 1034-1045.

32 BONFIM, Benedito Calheiros. Globalização, flexibilização e desregulamentação do direito do trabalho. In: MACCALÓz, Salete Maria et al. Globalização, neoliberalismo e direitos sociais. Rio de Janeiro: Destaque, 1997. p. 42-43.

${ }_{33}$ MACCALÓZ, Salete Maria Polita. Globalização e flexibilização. In: MACCALÓZ, Salete Maria et al. Globalização, neoliberalismo e direitos sociais. Rio de Janeiro: Destaque, 1997. p. 13. 
mudaria. No entanto, como em um passe de mágica, o que tinha uma aparência retrógrada e condenável aparece com ares de modernidade: insegurança no trabalho x flexibilidade no trabalho, insegurança do emprego x flexibilidade do emprego, insegurança da renda x flexibilidade da renda, insegurança da contratação x flexibilidade da contratação, insegurança na representação do trabalho x flexibilidade na representação do trabalho.

Não faltam diferentes acepções do conceito de flexibilização, embora a mais ao gosto dos organismos internacionais e dos economistas, portanto mais conhecida, identificaria dois tipos de flexibilidade. A primeira, dita numérica ou quantitativa, seria identificada como um conjunto de flexibilidades, internas e externas às empresas, ligadas aos salários e ao emprego, à contratação e à demissão, ao mercado de trabalho. A segunda forma de flexibilidade, chamada de funcional ou qualitativa, trataria mais da adaptabilidade da mão-de-obra, das diferentes formas de gestão, da qualificação, etc. ${ }^{34}$

No tocante ao mercado de trabalho, José Eduardo Faria discorre sobre os três níveis de manifestação da flexibilização:

Em termos de estrutura do mercado de trabalho, a "flexibilidade" tende a se dar em três níveis simultâneos: um núcleo cada vez menor de trabalhadores polivalentes estáveis, trabalhando em tempo integral com ampla "flexibilidade funcional]" dentro das empresas, desfrutando de direitos trabalhistas, gozando de benefícios sociais e dispondo de relativa segurança, assegurada pela dificuldade da sua substituição em face de sua qualificação, de sua experiência e de suas responsabilidades; uma mão-de-obra periférica de baixa qualificação, contratável e demissível segundo as conveniências das empresas, sem seguro-desemprego [...], flutuando ao acaso da conjuntura econômica ("flexibilidade numérica"); e os "trabalhadores externos" (eventuais ou temporários, pouco especializados, e contratados por tarefa), para os quais as empresas não têm maiores obrigações jurídicas. A figura metafórica mais persuasiva é a da ampulheta: a parte inferior conta com um número cada vez mais expressivo de trabalhadores divididos em empregos precários ou desempregados; o meio conta com um contingente cada vez menor de trabalhadores semiqualificados, quase todos virtualmente condenados à exclusão por causa da velocidade dos processos de informatização; a parte superior, por fim, integrada por trabalhadores poliqualificados e bem remunerados, tende a diminuir na mesma proporção em que o desenvolvimento científico-tecnológico amplia a automação flexível dos sistemas produtivos. ${ }^{35}$

Acerca da flexibilização dos direitos trabalhistas, José Affonso Dallegrave Neto desvenda os mecanismos das políticas neoliberais que se encontram presentes na sua concepção e implementação:

\footnotetext{
${ }^{34}$ MATTOSO, Jorge Eduardo Levi. Globalização, neoliberalismo e flexibilização. In: ARRUDA JÚNIOR, Edmundo Lima de; RAMOS, Alexandre (Org.). Globalização, neoliberalismo e o mundo do trabalho. Curitiba: IBEJ, 1998. p. 44-45.

${ }^{35}$ FARIA, José Eduardo. O Direito na economia globalizada. p. 230-231.
} 
Para nós a flexibilização da relação de trabalho é uma corrente doutrinária desenhada por juristas do novo paradigma neoliberal, patrocinada por empresários e organizações financeiras mundiais, que visa basicamente: a) desregulamentar a legislação trabalhista; b) estimular formas flexíveis de contratação de empregados e rescisões sem ônus e c) acabar com o princípio de proteção ao empregado - introduzido pelo paradigma do Estado Social Intervencionista, no início deste século.

Busca-se, assim, uma reaproximação do Direito do Trabalho com o Direito Civil.

Para Robortella, “as novas funções e técnicas do Direito do Trabalho... despertam para uma revalorização de institutos do direito civil antes desprezados, vistos agora como categorias jurídicas plenamente funcionais no campo trabalhista".

Mas quais são estes institutos civilistas que a flexibilização quer reimplantar no Jus Laboral: trata-se dos velhos dogmas da autonomia privada e do pacta sunt servanda. Com efeito, passa-se, neste quadrante, a ver o empregado no mesmo pé de igualdade jurídica que o empregador, não mais se justificando falar em proteção à parte mais frágil. ${ }^{36}$

Como corolário da agilidade e rapidez da transmissão das informações em âmbito mundial, características do fenômeno da globalização que contribuem para uma crescente interconexão em vários níveis da vida cotidiana a diversos lugares longínquos no mundo, Dallegrave Neto vislumbra que a composição dos litígios trabalhistas desloque-se da esfera estatal para o domínio privado, peculiaridade que é representativa do esvaziamento da seara política para a defesa dos direitos sociais relativos ao trabalho e da perda de séculos de lutas sociais:

[...] há que se registrar que à era da globalização está ínsita a instantaneidade das informações e das decisões. A partir desta exigência, o atual modelo judiciário tornou-se arcaico e anacrônico.

Com outras palavras, os neoliberais não admitem um Judiciário tão moroso para decidir a dissolução de uma empresa ou para declarar inviável ou não (inconstitucional) uma medida econômica, por exemplo. Passa-se, então, a estimular as chamadas medidas de autocomposição da lide (mediação, pactos coletivos, validade dos pactos individuais trabalhistas; fim do Poder Normativo, etc.) ou mesmo formas de solução extrajudicial (arbitragem, câmaras de conciliação, etc.). ${ }^{37}$

A globalização econômica e as políticas neoliberais contribuíram para o declínio do papel dos sindicatos na organização da classe traba-

\footnotetext{
${ }^{36}$ DALLEGRAVE NETO, José Affonso. O Estado neoliberal e seu impacto sócio-jurídico. In: MACCALÓz, Salete Maria et al. Globalização, neoliberalismo e direitos sociais. Rio de Janeiro: Destaque, 1997. p. 90.
} 
lhadora para a defesa das antigas conquistas político-jurídicas obtidas no seio do Estado moderno, tendo como resultado um quadro de exclusão social que rompeu os elos de solidariedade ${ }^{38}$ que ligavam os trabalhadores uns com os outros e que aglutinavam e catalisavam as reivindicações políticas e jurídicas que compartilhavam.

Boaventura de Sousa Santos faz uma leitura deste panorama, ligando estas mazelas à flexibilização das tutelas jurídico-trabalhistas e suas conseqüências nefastas no âmbito da cidadania:

O isolamento político das classes trabalhadoras na produção está obviamente ligado aos processos que acabei de descrever e constitui, de facto, a outra face da difusão social da produção. As várias dimensões da difusão social da produção contribuíram, cada uma a seu modo, para a transformação do operariado em mera força de trabalho. São particularmente importantes neste domínio as diferentes estratégias de flexibilização ou, melhor, de precarização da relação salarial que um pouco por toda a parte têm vindo a ser adoptadas: declínio dos contratos de trabalho por tempo indeterminado, substituídos por contratos a prazo e de trabalho temporário, pelo trabalho falsamente autónomo e pela subcontratação, pelo trabalho ao domicílio e pela feminização da força de trabalho (associadas em geral a uma maior degradação da relação salarial). Todas essas formas de relação salarial visam sujeitar os ritmos da reprodução social aos ritmos da produção ("há trabalho quando há encomendas"), um processo que podemos designar por regresso do capital variável. A síndroma de insegurança que ele gera entre as famílias trabalhadoras e a concorrência que cria entre elas têm-se revelado poderosos instrumentos de neutralização do movimento operário.

[...] Apesar de todas as diferenças, o regresso do princípio do mercado nos últimos vinte anos representa a reavalidação social e política do ideário liberal e, conseqüentemente, a revalorização da subjectividade em detrimento da cidadania. Também neste domínio a resposta do capital aproveita e distorce sabiamente algumas reivindicações dos movimentos contestatórios dos últimos trinta anos. A aspiração de autonomia, criatividade e reflexividade é transmutada em privatismo, dessocialização e narcisismo, os quais, acoplados à vertigem produtivista, servem para integrar, como nunca, os indivíduos na compulsão consumista. Tal integração; longe de significar uma cedência

\footnotetext{
37 DALLEGRAVE NETO, José Affonso. O Estado Neoliberal e seu impacto sócio-jurídico. In: MACCALÓZ, Salete Maria et al. Globalização, neoliberalismo e direitos sociais. Rio de Janeiro: Destaque, 1997. p. 97.

${ }^{38}$ Neste particular, Octavio lanni, na obra IANNI, Octavio. A era do globalismo. 3. ed. Rio de Janeiro: Civilização Brasileira, 1997. p. 151, assevera: "A rigor a flexibilização envolve todo um rearranjo interno e externo da classe operária, em âmbito nacional, regional e mundial. Modificam-se os seus padrões de sociabilidade, vida cultural e consciência, simultaneamente condições de organização, mobilização e reivindicação. Os padrões de trabalho, organização e consciência que se haviam produzido e sedimentado no âmbito da sociedade nacional, são reelaborados ou abandonados, já que a nova divisão transnacional do trabalho e produção, na fábrica, estabelece outros horizontes e limites de sociabilidade, organização e consciência. 'As empresas praticam uma estratégia de flexibilização em dois níveis simultâneos: o núcleo estável do pessoal da firma deve ter uma flexibilidade funcional; a mão-de-obra periférica, por seu lado, deve apresentar uma flexibilidade numérica. Em outros termos, em torno de num núcleo de trabalhadores estáveis, apresentando um amplo leque de qualificações, flutua uma mão-de-obra periférica, de qualificações menores e mais limitadas, submetida ao acaso da conjuntura'".
} 
materialista, é vivida como expressão de um novo idealismo, um idealismo objectístico. A natureza do consumo metamorfoseia-se. Para além de que alguns objectos de consumo não têm qualquer existência material (as imagens digitais, por exemplo), a retracção da produção em massa e a sua gradual substituição pela clientelização e personalização dos objectos transforma estes em características da personalidade de quem os usa e, nessa medida, os objectos transitam da esfera do ter para a esfera do ser. O novo subjectivismo e o culto dos objetos é o ersatz da intersubjectividade. Estas transformações são de tal modo profundas e arquetípicas que, para dar adequadamente conta delas, é necessário proceder a transformações profundas e arquetípicas na teoria sociológica. Nas condições sociais dos anos noventa, o idealismo será provavelmente a forma mais consequente de materialismo.

Nesta nova configuração simbólica, a hipertrofia do princípio do mercado assinala um novo desequilíbrio entre regulação e emancipação. Desta vez, o excesso de regulação reside em que subjectividade sem cidadania conduz ao narcisismo e ao autismo. ${ }^{39}$

Levando-se em consideração o que desenvolvemos até o momento no que tange à flexibilização e à desregulamentação do Direito do Trabalho, podemos vislumbrar que elas seriam o indicativo das práticas neoliberais no sentido de contribuir para solapar o poder do Estado, erodir a sua soberania e para esvaziar a arena política na medida que afastam cada vez mais os cidadãos da participação política, deixando-os à mercê de sua própria sorte, gerando, como decorrência, a exclusão social que se exacerba de forma exponencial. Neste contexto, a flexibilização da legislação trabalhista nada mais seria do que um eufemismo para a sua supressão dos direitos sociais ligados ao trabalho.

\section{Considerações finais}

Estas reflexões apresentadas até aqui contribuem para denunciar e desvendar o que existe por trás da globalização econômica, que constitui o papel do sociólogo segundo Pierre Bourdieu. ${ }^{40}$ Ao evidenciar as mazelas da globalização econômica no plano político-jurídico, não pretendemos dar uma resposta pronta acerca da temática, mas instigar a pensar-se sobre o novo panorama do mundo globalizado, sobretudo acerca dos perigos que vivenciamos a partir dessa realidade.

Quando nos referimos ao poder detido pelas empresas transna-

\footnotetext{
39 SANTOS, Boaventura de Sousa. Pela mão de Alice. p. 253, 255-256.

${ }^{40}$ Nosso propósito é produzir uma reflexão sobre o tema, fundada em argumentos científicos, consoante os ensinamentos de Pierre Bourdieu constantes na aula inaugural proferida no Collège de France que anteriormente fizemos referência, publicada no Brasil sob o título Lições de aula. 2. ed. São Paulo: Ática, é aquele que se esforça por dizer a verdade das lutas que têm como objeto — entre outras coisas - a

A \& C R. de Dir. Administrativo e Constitucional, Belo Horizonte, ano 6, n. 26, p. 37-58, out./dez. 2006
} 
cionais, não concebemos a existência de um "governo invisível das transnacionais" ou uma "teoria conspiratória das transnacionais", como muito bem advertem alguns autores. Pretendemos, na verdade, enfatizar que o poder local está enfraquecido em face da globalização econômica, na medida que as decisões transcendem a esfera estatal, eis que o grande crescimento do poder econômico mundial dificulta o seu controle, em razão da capacidade dos capitais cruzarem facilmente e de modo rápido as fronteiras. Como conseqüência, o poder eleito (representativo) acabou perdendo sua identidade, esvaziando-se e curvando-se a um poder que não possui representatividade, presente nas finanças que transitam ao redor do mundo. ${ }^{41}$

Além disso, a globalização econômica e as políticas neoliberais que a operacionalizam fazem com que as decisões de governo deixem de serem políticas para tornarem-se econômicas, baseadas numa relação custo/benefício.

Não entendemos que o processo de globalização seja uma "fatalidade irreversível”. Primeiramente, conforme muito bem salientou Hobsbawm, há limites históricos no processo de globalização, que se consubstanciam na "resistência política das pessoas afetadas". ${ }^{42}$ Além disso, na esteira do pensamento de Ignacio Ramonet, devemos considerá-lo como um "desafio a ser transposto" a partir do resgate da política. ${ }^{43}$

Assevera Francisco de Oliveira que "[...] a globalização, expressa privatização do público, ou, ideologicamente, uma experiência subjetiva de desnecessidade, do público". ${ }^{44}$ Esta reflexão, aliada às conseqüências negativas da globalização, permite-nos reafirmar o primado da política em todos os níveis, resgatando a primazia da política sobre a economia.

2003. p. 13-14, 25: "[...] Sem dúvida, o sociólogo não é mais o árbitro imparcial ou o espectador divino, o único a dizer onde está a verdade - ou, para falar em termos do senso comum, que tem razão - e isso leva a identificar a objetividade a uma distribuição eqüitativa dos erros e das razões. Mas o sociólogo é aquele que se esforça por dizer a verdade das lutas que têm como objeto — entre outras coisas — a verdade. Por exemplo: em lugar de estabelecer uma divisão entre aqueles que afirmam e aqueles que negam a existência de uma classe, de uma região ou de uma nação, trabalha no sentido de estabelecer a lógica específica dessa luta, e de determinar, através de uma análise do estado da relação de forças e dos mecanismos de sua transformação, as chances dos diferentes campos. Cabe-Ihe construir um modelo verdadeiro das lutas pela imposição da representação verdadeira da realidade, que contribuem para fazer a realidade tal como se apresenta ao registro" [...] "Se há uma verdade, é que a verdade é um resultado de lutas; mas essa luta só pode conduzir à verdade quando obedece a uma lógica tal que não se pode triunfar sobre os adversários sem empregar contra eles as armas da ciência, contribuindo assim para o progresso da verdade científica".

${ }^{41}$ Neste sentido, reportamo-nos ao artigo de RIBEIRO, Renato Janine. Um adeus à democracia. Folha de S.Paulo, São Paulo, 15 out. 1995. 5. caderno, p. 3.

42 HOBSBAWM, Eric J. O novo século. São Paulo: Cia. das Letras, 2000. p. 86-88.

${ }^{43}$ RAMONET, Ignacio. O pensamento único e os regimes globalitários. In: FIORI, José Luís et al. Globalização: o fato e o mito. Rio de Janeiro: EdUERJ, 1998. p. 59. 
E ao assim proceder-se, estaríamos trilhando um caminho no sentido de atenuar ou, até mesmo quem sabe, debelar as mazelas produzidas pela globalização, dentro da linha de ação concebida por Pierre Bourdieu: “[...] É preciso atuar sobre os Estados nacionais, por um lado para defender e reforçar as conquistas históricas associadas ao Estado nacional [...]" ${ }^{45}$

Temos convicção de que se procedermos desta forma, haverá condições de atenuar ou até mesmo reverter o panorama sinistro que a globalização econômica apresenta nas searas política e jurídica.

Ao apresentarmos o quadro funesto que se denota no plano políticojurídico com a globalização econômica, a presente reflexão visa alertar as suas conseqüências extremamente nefastas para o destino da humanidade. Mas, se tais ocorrências negativas continuarem se manifestando e recrudescerem, o homem poderia ser comparado com o aprendiz da balada imortal de que nos falou Couture, "que sabia provocar tempestades, porém não sabia como contê-las". ${ }^{46}$ Poderíamos usar também as palavras do aprendiz de feiticeiro de Goethe: "Os espíritos que eu chamei, destes não me livro mais".

Informação bibliográfica deste texto, conforme a NBR 6023:2002 da Associação Brasileira de Normas Técnicas (ABNT):

LIMA, Abili Lázaro Castro de. A globalização econômica e a dissipação dos direitos sociais. A\&C Revista de Direito Administrativo e Constitucional, Belo Horizonte, ano 6, n. 26, p. 37-58, out./dez. 2006.

\footnotetext{
44 OLIVEIRA, Francisco de. Privatização do público, destituição da fala e anulação da política: o totalitarismo neoliberal. In: OLIVEIRA, Francisco de; PAOLI, Maria Célia. Os sentidos da democracia: políticas do dissenso e hegemonia global. Petrópolis: Vozes, 1999. p. 57.

${ }^{45}$ BOURDIEU, Pierre. Por um novo internacionalismo. Contrafogos: táticas para enfrentar a invasão neoliberal. Rio de Janeiro: Zahar, 1998. p. 89.

${ }^{46}$ COUTURE, Eduardo. Os mandamentos do advogado. Porto Alegre: Sérgio Fabris, 1979. p. 42.
}

A \& C R. de Dir. Administrativo e Constitucional, Belo Horizonte, ano 6, n. 26, p. 37-58, out./dez. 2006 